Atmos. Chem. Phys., 18, 6259-6273, 2018

https://doi.org/10.5194/acp-18-6259-2018

(C) Author(s) 2018. This work is distributed under

the Creative Commons Attribution 4.0 License.

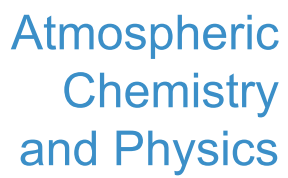

(c) (P)

\title{
The absorption Ångström exponent of black carbon: from numerical aspects
}

\author{
Chao Liu ${ }^{1,2}$, Chul Eddy Chung ${ }^{3}$, Yan Yin ${ }^{1,2}$, and Martin Schnaiter ${ }^{4}$ \\ ${ }^{1}$ Collaborative Innovation Center on Forecast and Evaluation of Meteorological Disasters, \\ Nanjing University of Information Science \& Technology, Nanjing 210044, China \\ ${ }^{2}$ Key Laboratory for Aerosol-Cloud-Precipitation of China Meteorological Administration, School of Atmospheric Physics, \\ Nanjing University of Information Science \& Technology, Nanjing 210044, China \\ ${ }^{3}$ Desert Research Institute, Reno 89512, USA \\ ${ }^{4}$ Karlsruhe Institute of Technology, Institute of Meteorology and Climate Research, 76021 Karlsruhe, Germany
}

Correspondence: Chao Liu (chao_liu@nuist.edu.cn)

Received: 7 September 2017 - Discussion started: 4 October 2017

Revised: 15 March 2018 - Accepted: 10 April 2018 - Published: 4 May 2018

\begin{abstract}
The absorption Ångström exponent (AAE) is an important aerosol optical parameter used for aerosol characterization and apportionment studies. The AAE of black carbon (BC) particles is widely accepted to be 1.0, although observational estimates give quite a wide range of $0.6-1.3$. With considerable uncertainties related to observations, a numerical study is a powerful method, if not the only one, to provide a better and more accurate understanding on BC AAE. This study calculates BC AAE using realistic particle geometries based on fractal aggregate and an accurate numerical optical model (namely the multiple-sphere T-matrix method), and considers bulk properties of an ensemble of BC particles following lognormal size distributions. At odds with the expectations, $\mathrm{BC} \mathrm{AAE}$ is not 1.0, even when $\mathrm{BC}$ is assumed to have small sizes and a wavelength-independent refractive index. With a wavelength-independent refractive index, the $\mathrm{AAE}$ of fresh $\mathrm{BC}$ is approximately 1.05 and relatively insensitive to particle size. For BC with geometric mean diameters larger than $0.12 \mu \mathrm{m}, \mathrm{BC}$ AAE becomes smaller when $\mathrm{BC}$ particles are aged (compact structures or coated by other non-absorptive materials). For coated BC, we prescribe the coating fraction variation based on a laboratory study, where smaller BC cores are shown to develop larger coating fractions than those of bigger BC cores. For both compact and coated $\mathrm{BC}$, the AAE is highly sensitive to particle size distribution, ranging from approximately 0.8 to even over 1.4 with wavelength-independent refractive index. When the refractive index is allowed to vary with wavelength, a feature
\end{abstract}

with observational backing, the BC AAE may show an even wider range. For different $\mathrm{BC}$ morphologies, we derive simple empirical equations on BC AAE based on our numerical results, which can serve as a guide for the response of $\mathrm{BC}$ $\mathrm{AAE}$ to $\mathrm{BC}$ size and refractive index. Due to its complex influences, the effects of BC geometry is better to be discussed at certain $\mathrm{BC}$ properties, i.e., known size and refractive index.

\section{Introduction}

The absorption Ångström exponent (AAE) is an aerosol optical property describing the wavelength variation in aerosol absorption. Because aerosol absorption normally decreases exponentially with wavelength over the visible and nearinfrared spectral region (Ångström, 1929; Bond, 2001; Lewis et al., 2008), the AAE is defined as

$$
\begin{aligned}
& C_{\mathrm{abs}}(\lambda)=C_{o} \lambda^{-\mathrm{AAE}} \quad \text { or } \\
& \ln \left(C_{\mathrm{abs}}(\lambda)\right)=\ln \left(C_{o}\right)-\mathrm{AAE} \ln (\lambda),
\end{aligned}
$$

where $\lambda, C_{\mathrm{abs}}$, and $C_{o}$ denote wavelength, the aerosol absorption coefficient, and a wavelength-independent constant (which equals the absorption coefficient at the wavelength of $1 \mu \mathrm{m})$. Instead of the absorption coefficient, some studies use the aerosol absorption optical depth in Eq. (1), because the two are proportional. The AAE describes absorption variation with respect to wavelength and is significantly 
influenced by particle size, shape, and chemical composition (Scarnato et al., 2013; Schuster et al., 2006; Li et al., 2016). The chemical composition of aerosol material determines the wavelength-dependent refractive index.

AAE has been widely used for aerosol characterization studies (Russell et al., 2010; Giles et al., 2012). The basis for the AAE in aerosol characterization is that AAE is assumed to be a specific property of each aerosol species. For example, black carbon (BC) aerosols have AAEs around 1.0, and organic aerosols and dust have higher AAE values (Kirchstetter et al., 2004; Russell et al., 2010). Thus, the AAE of an aerosol sample close to 1.0 is considered to be $\mathrm{BC}$-rich aerosol from fossil fuel burning, and larger AAE values are understood to indicate aerosols from biomass/biofuel burning or dust (Russell et al., 2010). AAE has also been quantitatively used to separate brown carbon $(\mathrm{BrC})$ absorption from BC absorption (Kirchstetter and Thatcher, 2012; Lu et al., 2015). In the studies of $\mathrm{BC} / \mathrm{BrC}$ absorption separation, the $\mathrm{BrC}$ absorption from biomass burning aerosols is usually retrieved by assuming that $\mathrm{BrC}$ contributes no absorption at near-infrared wavelengths and that $\mathrm{BC}$ has an AAE of 1.0 (Ganguly et al., 2005; Kirchstetter and Thatcher, 2012; Lu et al., 2015). Lack and Langridge (2013) quantified the effect of a specified BC AAE value on the absorption apportionment between $\mathrm{BC}$ and $\mathrm{BrC}$ and demonstrated the importance of BC AAE. Additional uses of AAE include aerosol color. A recent numerical study done by C. Liu et al. (2016), for example, confirms that AAE largely controls the color of aerosols in the ambient atmosphere. They found that aerosols are visually brown if their AAE is larger than approximately 2. In another use, aerosol spectral light absorption is an important parameter for the assessment of the radiation budget of the atmosphere (Schmid et al., 2006).

$\mathrm{BC}$, also known as soot, is an important aerosol species emitted from incomplete combustion of fossil fuel, biofuel, and biomass (Bond and Sun, 2005; Bond et al., 2013; Chakrabarty et al., 2014), and it exhibits significant variations in its physical and chemical properties due to differences in fuels and combustion conditions (Schnaiter et al., 2006; Bahadur et al., 2012; Reddington et al., 2013). Does $\mathrm{BC}$ indeed have an AAE of 1.0? The AAE of BC from combustion is widely accepted and used as 1.0 when the particles exist alone and have not experienced atmospheric aging processes (Bergstrom et al., 2002, 2003; Schnaiter et al., 2003; Lawless et al., 2004; Bond and Bergstrom, 2006). If BC particles are much smaller than the incident light wavelength and have a wavelength-independent refractive index, the Rayleigh approximation does theoretically derive an AAE of 1.0 (Moosmüller and Arnott, 2009). Atmospheric BC particles are generally small compared to the wavelengths of visible light, but it is uncertain that all the BC particles clearly fall into the Rayleigh regime. Furthermore, there is much uncertainty in the wavelength dependence of the $\mathrm{BC}$ refractive index. In reality, $\mathrm{BC}$ aggregates in the ambient atmosphere may just fall at the edge of the Rayleigh region at visible and near-infrared wavelengths. Figure 1 visualizes the extent to which the Rayleigh approximation holds for spheres by comparing with the exact Mie results. In Fig. 1, the $x$ axis represents the particle size parameter, defined as $2 \pi r / \lambda$ with $r$ and $\lambda$ being radius and wavelength, respectively. We can see from Fig. 1 that the Rayleigh approximation is only valid for absorption if the size parameter is less than 0.2. To be more specific, an aerosol sphere with a radius of $20 \mathrm{~nm}$ corresponds to a size parameter of approximately 0.13 at a wavelength of $1000 \mathrm{~nm}$, at which the Rayleigh and Mie results agree quite well. However, if the wavelength decreases to $300 \mathrm{~nm}$, the size parameter of the same sphere increases to 0.42 , and the Rayleigh approximation underestimates the absorption by over $10 \%$. BC particles from combustion processes are aggregates composed of hundreds or even thousands of spherical monomers with radii in the range of about 5 to $25 \mathrm{~nm}$, and even these monomers lies out of the Rayleigh regime. The BC aggregate can easily have radii over $100 \mathrm{~nm}$, which makes the Rayleigh theory even less applicable to BC absorption calculation. Note that BC size will be discussed in detail in the next section.

When the true BC AAE is in doubt, one can alternatively investigate it by measuring the absorption of $\mathrm{BC}$ particles in the atmosphere, which turns out to be more challenging. BC AAE has been experimentally investigated in numerous studies (e.g., Schnaiter et al., 2003; Kirchstetter et al., 2004; Bahadur et al., 2012; Chung et al., 2012). In a laboratory study, Schnaiter et al. (2003) found diesel soot to have an AAE of 1.1 and spark-generated carbon nanoparticles to have an AAE of 2.1. The different AAE values were mainly attributed to differences in the wavelength dependence of the refractive index for the two BC materials. In the atmosphere, however, $\mathrm{BC}$ particles always co-exist with other aerosol particles. Non-BC particles can affect the total aerosol AAE by containing $\mathrm{BrC}$ or mineral dust (which have higher AAE values) and also by coating BC. Coating of $\mathrm{BC}$ amplifies the $\mathrm{BC}$ absorption, and the amplification of $\mathrm{BC}$ absorption is dependent on wavelength. Kirchstetter et al. (2004) measured the absorption of particles near a roadway or inside a tunnel and, after extracting organic carbon (including absorptive $\mathrm{BrC}$ ), found the AAE to be 0.6-1.3. The locations Kirchstetter et al. (2004) chosen would have yielded $\mathrm{AAE}$ without much interference from $\mathrm{BrC}$ or coating. However, Kirchstetter et al. (2004) used filter-based instruments to measure the absorption. Filter-based absorption instruments are susceptible to multiple artifacts such as optical interactions between the concentrated particle themselves and that of the particles with the filter substrate (Moosmüller et al., 2009). In addition, filter deposition may alter particle shapes and size distributions greatly (Subramanian et al., 2007), which affects aerosol absorption properties significantly (Li et al., 2016). Weingartner et al. (2003) and Arnott et al. (2005), for example, attempted to address these artifacts. The available correction schemes are not available for every type of $\mathrm{BC}$ and furthermore not optimized for adjusting 


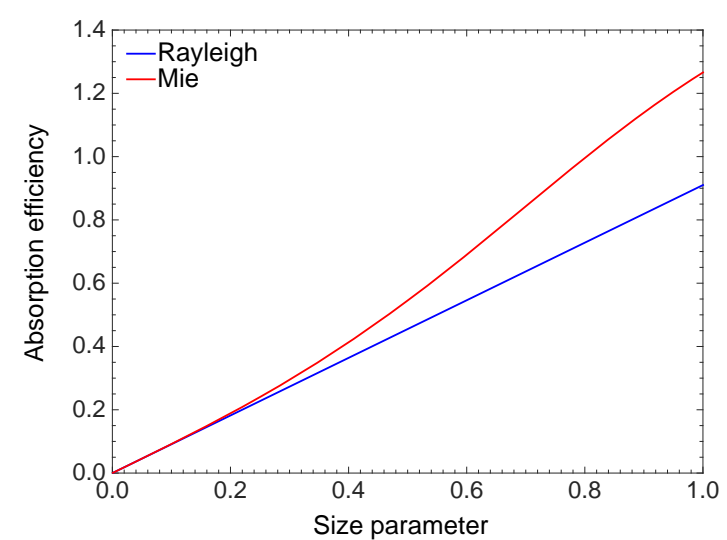

Figure 1. Comparison of the Rayleigh approximation and Mie theory for the absorption efficiency of spheres with a refractive index of $1.8+0.6 i$.

AAE. Chow et al. (2009) showed that a particle soot absorption photometer (PSAP), after an absorption artifact correction, gave AAE values about $20 \%$ less than a filter-free photoacoustic instrument for the aerosols at Fresno, California. Gyawali et al. (2012) and Chakrabarty et al. (2013) generated $\mathrm{BC}$-dominated particles by burning oil and measured the absorption using filter-free photoacoustic instruments. The estimated AAE ranged from 0.8 (kerosene soot) to $0.95-1.1$ (mustard oil soot). Because there must be some absorptive organic aerosols (e.g., $\mathrm{BrC}$ ) in these aerosol samples that have a much larger AAE, the indication from these two studies is that BC AAE is lower than 0.8-1.1.

In addition, AAE values could differ due to differences in AAE calculations. For example, if the absorptions at two wavelengths are observed, the AAE can be approximated by

$\mathrm{AAE}=-\frac{\ln \left(C_{\mathrm{abs} 1} / C_{\mathrm{abs} 2}\right)}{\ln \left(\lambda_{1} / \lambda_{2}\right)}$,

where $C_{\mathrm{abs} 1}$ and $C_{\mathrm{abs} 2}$ are the absorption coefficients at the wavelengths of $\lambda_{1}$ and $\lambda_{2}$, respectively. Due to the variation in different ranges of wavelengths, the AAE approximated by Eq. (2) becomes quite sensitive to the choice of observational wavelengths (Moosmüller and Chakrabarty, 2011).

Whether BC AAE is exactly 1.0 or not is an issue we will address in this paper. Another issue is whether BC coated with non-absorptive material would have the same $\mathrm{AAE}$ as uncoated $\mathrm{BC}$. In the aforementioned $\mathrm{BC} / \mathrm{BrC}$ absorption separation studies (Kirchstetter and Thatcher, 2012; Lu et al., 2015), the AAE for uncoated BC was implicitly assumed to be the same as that for coated BC. Lack and Cappa (2010) used a core-shell Mie code to investigate how BC changes its $\mathrm{AAE}$ value with respect to coating. At realistic particle sizes, they showed that the BC AAE increases to 1.4-1.6 after coating. They computed $\mathrm{BC}$ AAE using a group of $\mathrm{BC}$ particles where the cores were specified to have a lognormal size distribution. In their study, coating volume fraction was assumed to be fixed for all the particles, an assumption that has no experimental, observational, or theoretical support. When BC particles grow in size by coating, the particle growth is governed by condensation. Theoretically, condensation reduces the diameter spread between big particles and small particles over time (Seinfeld and Pandis, 2016), in contrast to the assumption by Lack and Cappa (2010). Schnaiter et al. (2005) coated BC particles with secondary organic aerosol material in a lab and found that the coating increases particle sizes, while it reduces geometric standard deviation (see Fig. 5 of their paper), as predicted by theoretical calculation of condensation process. Their work provided a meaningful experimental dataset to derive coating fraction variation in BC particles. Furthermore, Schnaiter et al. (2005) also measured the absorption of coated BC particles at 450, 550, and $700 \mathrm{~nm}$ (see Fig. 9 of their paper), and from these three wavelengths we see that coating does actually decrease BC AAE (from approximately 1.1 to 0.8 ), thereby contradicting the coated BC AAE estimates in the study by Lack and Cappa (2010). This indirectly indicates that a fixed coating fraction for different-sized BC may be problematic.

Although observations do not give a clear value of $\mathrm{BC}$ $\mathrm{AAE}$, it is safe to say that even accurate observations do not strongly support the theoretical constant of 1.0 for BC AAE. The fact alone that there are different types of soot particles (associated with different refractive indices) points to a range of BC AAE instead of a fixed value. Furthermore, it is not clear if the real BC AAE is 1.0 on average. Despite all these uncertainties, BC AAE has been assumed to be 1.0 in many studies (Lack and Langridge, 2013; Moosmüller et al., 2009; Lack et al., 2008; Kirchstetter et al., 2004; Lewis et al., 2008). Meanwhile, numerical studies on BC AAE have shown neither systematic nor conclusive results to improve our understanding on them (Li et al., 2016; Lack and Langridge, 2013).

This study presents a systematic numerical investigation on the AAE of BC particles and decomposes the AAE influence into that due to each particle microphysical property (e.g., shape, size, refractive indices, and internal mixing). The paper is organized as follows. The properties of BC particles used for absorption simulations are discussed in Sect. 2, and Sect. 3 presents the AAE simulations and decomposes the AAE influences. Section 4 concludes this study.

\section{BC properties}

The absorption of a single particle or an ensemble of particles can be accurately calculated if the particle shape, size, and refractive index are known. With a large amount of observations on BC microphysical and optical properties made in the past decades (Sorensen, 2001; Bond and Bergstrom, 2006), there is much less uncertainty in estimating shape, size, and refractive index for $\mathrm{BC}$ compared with AAE es- 
timation. The present study embarks on numerical calculations of the optical properties of an ensemble of BC particles. There have been numerous calculations of BC optical properties on a single wavelength (Sorensen, 2001; Liu and Mishchenko, 2005, 2007; Smith and Grainger, 2014), and the novelty of the present study is considering much wider but realistic ranges of $\mathrm{BC}$ properties (especially the particle shape and coating fraction) and focusing on AAE systematically. The following subsections discuss BC geometry, size, and refractive index and explain how these properties are treated in the simulations herein.

\subsection{BC geometry}

BC particles exist in the form of aggregates with hundreds or even thousands of small spherical particles, called monomers. The concept of the fractal aggregate (FA) shows great success and wide applications on representing realistic BC geometries (Sorensen, 2001). The FA is mathematically described by the statistic scaling rule in the form of

$N=k_{\mathrm{f}}\left(\frac{R_{\mathrm{g}}}{a}\right)^{D_{\mathrm{f}}}$,

where $N$ is the number of spherical monomers in an aggregate, $a$ the average radius of the monomers, $R_{\mathrm{g}}$ the radius of gyration, $k_{\mathrm{f}}$ the fractal prefactor, and $D_{\mathrm{f}}$ the fractal dimension. Based on Eq. (3), as $k_{\mathrm{f}}$ or $D_{\mathrm{f}}$ increases, a relatively small $R_{\mathrm{g}}$ is required for fixed $N$ and $a$, which corresponds to a relatively compact particle. The non-idealized factors, such as overlapping or necking among monomers, nonsphericity, and monomer size dispersion, do exist in reality, and their effects on BC optical properties have been extensively studied (Skorupski and Mroczka, 2014; Yon et al., 2015; Wu et al., 2016; C. Liu et al., 2015; F. Liu et al., 2016). It is found that their effects on the absorption are minor compared with those of the overall geometry or size. Thus, we ignore those minor geometric factors in the aggregates and assume FA to be perfectly aggregated (point-to-point attachment without overlapping) by same-sized spherical monomers.

Immediately after being emitted into the atmosphere, BC aggregates exhibit lacy structures with a small fractal dimension $D_{\mathrm{f}}$, normally less than 2 (Sorenson, 2001; Chakrabarty et al., 2009). We refer to these lacy-structured BC aggregates as fresh BC here. Over time, the structure and chemical composition of $\mathrm{BC}$ particles change, i.e., a process called "aging". Aged BC particles normally have structures of compact aggregates coated by other material (Moffet and Prather, 2009). We refer to these particles as coated BC. In some cases (such as humidified biomass burning aerosols), aged BC particles have structures of compact aggregates without coating (Lewis et al., 2009). We refer to these uncoated aged particles as compact BC.

The optical properties of the mixed $\mathrm{BC}$ were investigated by a core-shell model with a Mie theory in the past, which assumes a spherical BC core in the center of coating sphere
(Chung et al., 2012; Lack et al., 2012; Peng et al., 2016; Moffet and Prather, 2009), and this may introduce significant differences on BC optical properties. Meanwhile, some studies have introduced more complex and realistic geometries to consider the effects of coating on BC optical properties (Liu et al., 2012; F. Liu et al., 2016; Dong et al., 2015), whereas the AAE was not explored. For coated BC, this study uses a compact aggregate as the $\mathrm{BC}$ core, and a spherical coating is added as the coating material following the numerical model developed by C. Liu et al. (2017). The coating is assumed to be non-absorptive sulfate, the wavelength-dependent refractive indices of which are obtained from the well-known aerosol optical property database OPAC (Hess et al., 1998). The real part of sulfate refractive index decreases slightly from 1.47 to 1.42 as the wavelength increases from 0.3 to $1.0 \mu \mathrm{m}$.

However, the amount of coating, another important factor to determine the absorption enhancement, is one of the most poorly investigated issues for coated BC (D. Liu et al., 2017). The key issue here is to develop a relationship between core size and coating amount for a group of differentsized BC particles. In other words, after fresh BC particles become coated over a certain amount of time, do small cores tend to have the same coating amount as big cores? Or do small cores have larger coating fractions than those of big cores? As pointed out in Sect. 1, if coating volume fraction is assumed to be fixed for different core sizes, modeled AAE variation is different from observations (Lack and Cappa, 2010). On the other hand, if we apply aerosol condensation physics, we speculate that small core particles are associated with larger coating amount, since condensation reduces the diameter differences between big and small particles. Thus, a more realistic and observation-based relationship between $\mathrm{BC}$ core size and coating amount should be derived.

We choose to use the experiment results by Schnaiter et al. (2005), because they gave the size distributions of the fresh and coated BC in a closed chamber environment. They coated diesel soot particles with secondary organic compounds produced by in situ ozonolysis of $\alpha$-pinene in a large aerosol chamber facility, and BC particles were aged for $24 \mathrm{~h}$. Figure 5 of their paper shows how the BC size increases as coating progresses. Lognormal size distributions were fitted based on the experimental data, and, during the $24 \mathrm{~h}$ aging process, the geometric mean diameter (GMD) was observed to increase from approximately 0.2 to $0.4 \mu \mathrm{m}$, demonstrating the effect of coating. Meanwhile, the geometric standard deviation (GSD) decreased from approximately 1.7 to 1.2 . The pair of BC size distributions before and after $24 \mathrm{~h}$ of coating is shown in Fig. 2a. However, Schnaiter et al. (2005) used a scanning mobility particle sizer (SMPS) to measure particle size, so the measured size is the mobility diameter $\left(D_{\mathrm{m}}\right)$. For thickly coated BC (i.e., BC after $24 \mathrm{~h}$ of coating), it can be safely assumed that the mobility diameter equals the diameter of an equivalent volume sphere $\left(D_{\text {equ }}\right)$, because thickly coated $\mathrm{BC}$ particles are highly compact and almost spherical. 

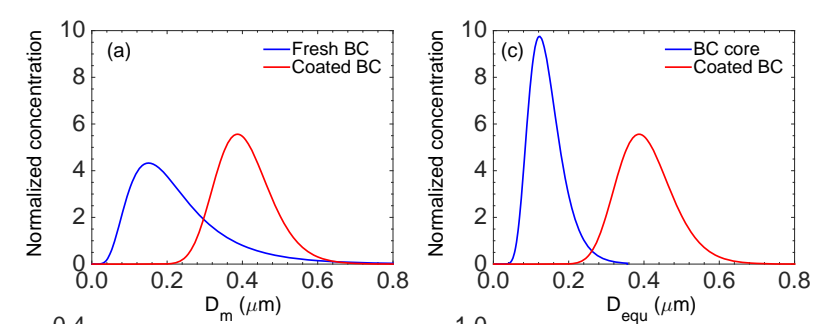

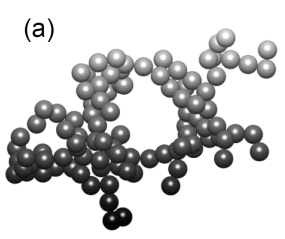

(b)
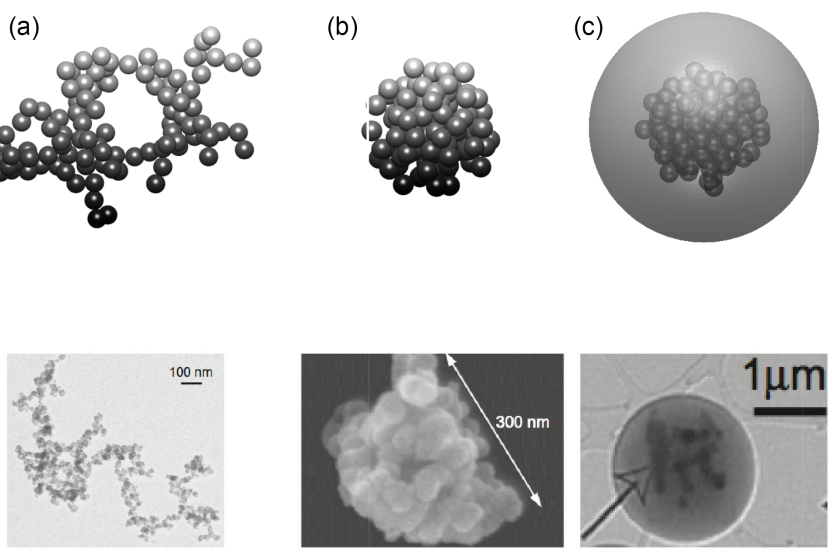

Figure 3. Geometries of numerically generated $\mathrm{BC}$ aggregates with different particle geometries, i.e., loose aggregate (a) for fresh BC, compact aggregate (b) for compact $\mathrm{BC}$, and coated aggregate (c) for coated BC, and some examples of realistic BC images for comparison (Burr et al., 2012; Lewis et al., 2009; Freney et al., 2010). Again, the monomer diameters are assumed to be $30 \mathrm{~nm}$. A fractal dimension of 1.8 is assumed for the fresh $\mathrm{BC}$, and 2.8 is used for the compact and coated $\mathrm{BC}$ particles.

tionship between the diameter of equivalent volume sphere $\left(D_{\text {equ }}\right)$ and mobility diameter $\left(D_{\mathrm{m}}\right)$ for fresh BC aggregates. (c) The size distributions for the diameters of the equivalent volume spheres ( $D_{\text {equ }}$ ) of BC core and coated BC after $24 \mathrm{~h}$ coating, based on panels (a) and (b). (d) Estimated volume fractions of BC core and coating material as a function of $D_{\text {equ }}$ of BC core, based on panel (c).

Thus, the size distribution measured by the SMPS after $24 \mathrm{~h}$ of coating can directly represent the equivalent volume size distribution of coated BC (i.e., $D_{\text {equ }}$ is following a lognormal distribution with a GMD of $0.4 \mu \mathrm{m}$ and a GSD of 1.2).

By assuming that, during the $24 \mathrm{~h}$ of coating, there was no particle coalescence or coagulation, the size distribution of fresh $\mathrm{BC}$ can be taken to represent that of $\mathrm{BC}$ cores of coated BC. For fresh BC, however, the mobility diameter deviates substantially from the diameter of equivalent volume sphere due to the lacy aggregation structures, and the latter is what we actually need in order to derive the BC core size distribution. To estimate the equivalent volume diameter of $\mathrm{BC}$ core (i.e., fresh $\mathrm{BC}$ ), we first convert the mobility diameter of fresh $\mathrm{BC}$ aggregates to monomer number, and this is achieved by applying Eqs. (5) and (21) in Naumann (2003), which use the fractal geometric parameters of diesel soot aggregates (Schnaiter et al., 2003). Then, the equivalent volume diameter can be obtained by assuming the $D_{\text {equ }}=2 a N^{-3}$ relation, and Fig. 2b illustrates the resulting relationship between $D_{\mathrm{m}}$ and $D_{\text {equ }}$ of BC core, i.e., fresh BC. As expected, $D_{\text {equ }}$ of fresh BC becomes much smaller than $D_{\mathrm{m}}$ as the particles become larger. Finally, the size distributions of $D_{\text {equ }}$ for $\mathrm{BC}$ core and coated $\mathrm{BC}$ are both obtained, and they are illustrated in Fig. 3c.

In addition, we are applying the following two simplifying assumptions to map the core size distribution into the size distribution of the coated BC. (1) Large BC cores are still larger than small $\mathrm{BC}$ cores after coating, i.e., BC cores

from the left or right side of the core size distribution will appear on the left or right side of the coated BC distribution, respectively. (2) For each single BC core size there exists only one single coating amount, i.e., applying a "one-to-one" mapping between core size and coating amount. With those two assumptions, the resulting equivalent volume diameter distribution of the BC core ( $D_{\text {equ, }} \mathrm{BC}$ core $)$ is mapped to that of the coated BC ( $\left.D_{\text {equ, coated BC }}\right)$, and the core-size-dependent coating amount can be calculated. As a result of this procedure, it is straightforward to estimate the $\mathrm{BC}$ core volume fraction in the coated $\mathrm{BC}$ particles: $V_{\mathrm{BC} \text { core }} / V_{\text {coated_BC }}=$ $\left(D_{\text {equ, BC }} \text { Bre } / D_{\text {equ, coated_BC }}\right)^{3}$, and the volume fractions of $\mathrm{BC}$ core and coating as a function of $D_{\text {equ, BC core }}$ are visualized in Fig. 2d. As Fig. 2d shows, small BC cores sized in $30-50 \mathrm{~nm}$ in equivalent volume sphere diameter account for less than $1 \%$ of the total volume, while large BC cores sized in $300-330 \mathrm{~nm}$ explain about $10 \%$ of the total coated BC particle volume. The relationship between $\mathrm{BC}$ core size and the coating volume fraction agrees with the trend obtained by Fierce et al. (2016), who used a particle-resolved numerical model. The derived relationship between $\mathrm{BC}$ core size and the coating volume fraction, as shown in Fig. 2d, is the first experiment-based one to our knowledge, and as such we view it as realistic. Please note that the coated $\mathrm{BC}$ considered in this study (i.e., coating after $24 \mathrm{~h}$ ) represents a case study (resembling the findings presented by Schnaiter et al., 2005) to give insights into the effects of coating on BC AAE. In real atmosphere, aged $\mathrm{BC}$ particles have extremely different and complex shapes and coating amounts (D. Liu et al., 2017), both of which may significantly influence the optical properties as well as the AAE. 
Figure 3 visualizes some examples of $\mathrm{BC}$ particles to illustrate the three $\mathrm{BC}$ formats, i.e., geometries considered in this study. A tunable particle-cluster aggregation algorithm is applied to generate the FAs (Filippov et al., 2000; Liu et al., 2012), and the coating sphere is added with its center located at the mass center of compact FA. Three transmission or scanning electron microscope images of $\mathrm{BC}$ particles are also given in the figure for comparison (Burr et al., 2012; Lewis et al., 2009; Freney et al., 2010), and we can see that the numerically generated particles have similar structures to those observed ones. Geometric parameters for FA with observational bases have been widely used for numerical studies (Liu and Mishchenko, 2005; Smith and Grainger, 2014; Li et al., 2016), and are also applied here to represent realistic BC particles. Specifically, the diameter of each monomer is set to $30 \mathrm{~nm}$ as supported by observations (Brasil et al., 2000; Chakrabarty et al., 2014), and the fractal prefactor of 1.2 that was estimated by Sorensen and Roberts (1997) is used. For the lacy aggregate, a fractal dimension of 1.8 , close to the is observed average by Köylü et al. (1995) and Sorensen and Roberts (1997) and both the compact and coated BC particles use a fractal dimension of 2.8 to make the $\mathrm{BC}$ particles as compact as we can. With the coating fraction as a function of the BC core size given in Fig. 2d, the aggregates are completely wrapped inside the coating sphere. Nevertheless, to better understand the sensitivity of BC AAE to geometries parameters, we will also explore other monomer diameters (i.e., 20 and $40 \mathrm{~nm}$ ) and another fractal dimension of 2.3 (i.e., the mean value between the two extreme values and the value derived from observation of Wang et al., 2017).

\subsection{BC size distribution}

Particle size distribution is one of the most commonly measured variables for aerosol studies. Aerosol size measuring instruments (such as the SMPS mentioned above, and the single-particle soot photometer, i.e., SP2, and electron microscopy) have repeatedly shown that a lognormal size distribution is a good fit for realistic BC size distributions (Bond et al., 2002; Schnaiter et al., 2005; Chakrabarty et al., 2006; Kirchstetter and Novakov, 2007; Reddington et al., 2013; Wang et al., 2015), and it is also widely used in numerical calculations of BC radiative properties and forcing (Moffet and Prather, 2009; Chung et al., 2012; Li et al., 2016). It should be noted that various different quantities are used to describe $\mathrm{BC}$ size distribution according to the principle used for the measurement. For example, as noted before, the SMPS measures the mobility equivalent diameters $D_{\mathrm{m}}$, which is quite sensitive to the particle shape, the SP2 gives the mass equivalent diameter of $\mathrm{BC}$ and $\mathrm{BC}$ cores (Reddington et al., 2013; Wang et al., 2015), and the projected areas deduced from $\mathrm{BC}$ micrographs are also used to understand its size distributions (Chakrabarty et al., 2006). Overall, BC diameters from a few tens to almost $1000 \mathrm{~nm}$ are obtained (Schnaiter et al., 2005; Chakrabarty et al., 2006; Kirchstet- ter and Novakov, 2007; Reddington et al., 2013; Wang et al., 2015).

To specify and unify the definition, all sizes in this study are referred to as the diameter of equivalent volume sphere from here on. For fresh or compact BC, this diameter can be given as $2 a \sqrt[3]{N}$, and, to ensure conservation of both mass and size distribution for comparison among fresh, compact and coated $\mathrm{BC}$, the size of coated $\mathrm{BC}$ will also be defined as that of the $\mathrm{BC}$ core. With the relationship between the coating fraction and $\mathrm{BC}$ core size given in Fig. 2d, it is straightforward to derive the overall size of coated $\mathrm{BC}$ with the diameter of bare BC part known. A median size and a standard deviation are used to describe the lognormal size distribution and to obtain the bulk absorption of an ensemble of BC particles. The GMDs between 0.10 and $0.12 \mu \mathrm{m}$ are most widely observed and used for numerical study (Alexander et al., 2008; Coz and Leck, 2011; Reddington et al., 2013; Wang et al., 2015), and the GSD values vary within a relatively narrow range. As the advantage of numerical study, we consider a relatively wide range of particle size distributions with the GMDs between 0.05 and $0.20 \mu \mathrm{m}$ for sensitivity purposes, and a fixed GSD of 1.5 is assumed. For BC core with GMDs between 0.05 and $0.20 \mu \mathrm{m}$ and a GSD of 1.5, the corresponding coated $\mathrm{BC}$ with the aforementioned coating faction has overall GMDs between 0.15 and $0.28 \mu \mathrm{m}$ and GSDs of approximately 1.2 .

For aggregates with fixed monomer sizes (diameter of $30 \mathrm{~nm}$ without special mention, and 20 and $40 \mathrm{~nm}$ used for sensitivity studies), their diameters are only determined by the number of monomers in the aggregate. We consider aggregates with the number of monomers ranging from 1 to 2000, corresponding to diameters of equivalent volume spheres from 0.03 to almost $0.4 \mu \mathrm{m}$. For example, with a monomer diameter of $30 \mathrm{~nm}$, an aggregate with approximately 300 monomers corresponds to an equivalent-volume sphere with a diameter of $0.2 \mu \mathrm{m}$. Numerical integrations can be easily carried out to obtain the bulk absorption of an ensemble of aggregates with a given size distribution. Again, for coated $\mathrm{BC}$, the size distribution is applied for only the $\mathrm{BC}$ core to make the $\mathrm{BC}$ amount and $\mathrm{BC}$ size distribution conserved.

\subsection{BC refractive index}

The refractive index (RI), a wavelength-dependent complex variable, is one of the most important parameters to determine aerosol AAE, because the absorptions at different wavelengths are significantly influenced by both the real and imaginary parts of RI. However, it is also one of the most uncertain physical properties of $\mathrm{BC}$ particles, because it cannot be directly observed. Estimates of BC RI have been normally made from observed absorption, scattering (or extinction), and size distribution of suspended particles, or from reflectance measurements on compressed $\mathrm{BC}$ pellets, and the $\mathrm{RI}$ is inferred by obtaining a best fit to numerical simulations 
(either Mie theory by assuming spherical particle shape or the simple Rayleigh-Debye-Gans theory) (Chang and Charalampopoulos, 1990; Schnaiter et al., 2003, 2005; Kirchstetter et al., 2004; Dalzell and Sarofim, 1969; Stagg and Charalampopoulos, 1993; Vanhulle et al., 2002; Moteki et al., 2010). Some of those studies extend RIs at particular wavelengths into the whole spectrum by the dispersion equations or the Kramers-Kronig analysis (Dalzell and Sarofim, 1969; Querry, 1987; Chang and Charalampopoulos, 1990). These retrieval methods based on the unrealistic spherical shape assumption or inaccurate numerical modeling pose sizable errors on estimated RIs, even without considering the error in aerosol optical property measurement. Furthermore, the BC materials from different combustions probably have different RIs, and this was discussed in the past (e.g., Sorensen, 2001; Bond and Bergstrom, 2006). After development over almost half a century, there are numerous datasets available with $\mathrm{BC}$ RIs over the entire solar spectrum to obtain optical properties for radiative applications related to BC (d'Almeida et al., 1991; Krekov, 1993; Hess et al., 1998). More details on the BC RIs have been carefully reviewed and summarized by Sorensen (2001) and Bond and Bergstrom (2006).

Figure 4 compares BC RIs from those cited studies. Most observation-based studies give RIs at some specific wavelengths, at which the observations are carried out, and some fitted results with continuous variations are also given. Both real and imaginary parts of the $\mathrm{BC}$ particles show quite wide ranges of variations, and we eliminated results with a real part much larger than 2 and an imaginary part much smaller than 0.5. The real part generally varies between 1.5 and 2.0. The imaginary part shows similar range of variation, and values from 0.5 to 1.1 have been retrieved. Furthermore, none of these datasets show a wavelength-independent RI, and quite different variations over the wavelength are shown in the figure. The real part of RI generally increases as the wavelength becoming larger, whereas the slopes of the variations are quite different. However, both increasing and decreasing trends are noticed for the imaginary part of RI. The figure clearly shows the uncertainties and large variations in BC RI, which brings the most significant challenge in approximating its AAE.

In view of Fig. 4, it is difficult to find a single value to represent BC RI, whereas it is doable to give a reasonable range of variation for numerical investigation. Considering the significant uncertainty in estimated BC RI due to differences on combustion fuels and conditions as well as whether BC is fresh or aged, we consider both wavelength-independent (i.e., constant) and wavelength-dependent RIs and introduce two parameters to indicate the variation in the real and imaginary part as wavelength, respectively. The real and imaginary part are defined as

$\operatorname{Re}(\lambda)=\operatorname{Re}_{o}+A(\lambda-0.55)$,
$\operatorname{Im}(\lambda)=\operatorname{Im}_{o} \times 10^{B(\lambda-0.55),}$
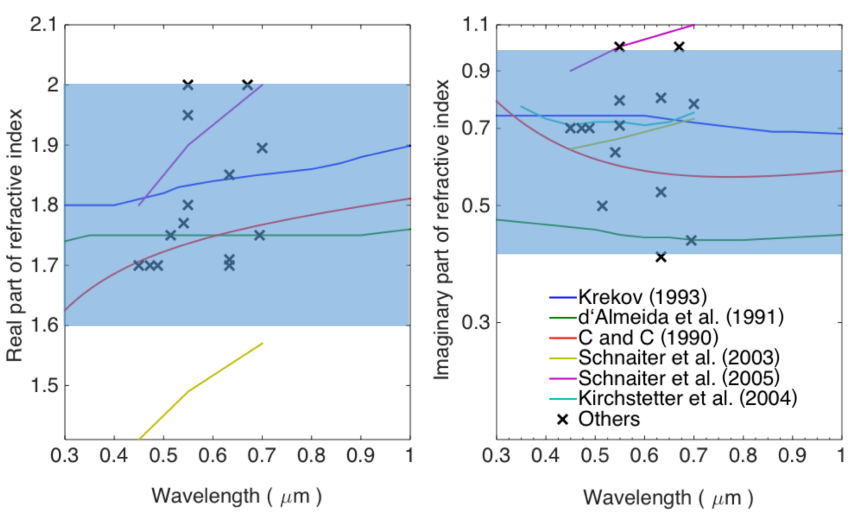

Figure 4. The real and imaginary parts of $\mathrm{BC}$ refractive indices from various observations. The blue shadow depicts the ranges considered in this study.

where $\lambda$ denotes wavelength in units of microns. $A$ and $B$ represent the wavelength dependence, and are defined independently. We use $0.55 \mu \mathrm{m}$ as the reference wavelength, and $\mathrm{Re}_{o}$ and $\operatorname{Im}_{o}$ can be understood as the real and imaginary part of RI at $0.55 \mu \mathrm{m}$. If $A=B=0$, the BC RI becomes wavelength independent. The real part of RI is simply assumed to vary linearly with wavelength, and the imaginary part is linear in the logarithmic scale. Because the range of wavelength we consider is relatively narrow, i.e., visible and near-infrared range, the simple assumption can capture the general variation in BC RIs. The corresponding $A$ and $B$ values for the RI shown in Fig. 4 are listed in Table 1, and the results from the various datasets show quite different values. It should be noticed that Schnaiter et al. $(2003,2005)$ give $A$ and $B$ much larger than those of other datasets. Besides Schnaiter et al. (2003, 2005), $A$ and $B$ values in the range of $(0.0,0.25)$ and $(-0.25,0.0)$, respectively, are enough to account for the RI wavelength dependence of other datasets. In light of the RI estimates made by previous studies, both $A$ and $B$ are assigned to be in the range of -0.5 and 0.5 here, which gives a much wider range of variation than those shown in Fig. 4 (besides those from Schnaiter et al., 2003, 2005). The shadow areas in Fig. 3 represent the large range of RIs that is considered in this study, and the areas clearly cover most previous BC RI estimates. It should be noticed that the real and imaginary parts of RI do not change independently (Bond and Bergstrom, 2006; Moteki et al., 2010), and $A$ and $B$ can only change with the limitations of the dispersion equations or the Kramers-Kronig analysis. However, we want to take the advantage of numerical models to better understand the effects of each parameter on BC AAE, and thus $A$ and $B$ are assumed here to be independent. This may lead to an overestimation of the AAE variability due to nonrealistic RI. 
Table 1. Fitted values for the parameters $A$ and $B$ used to define the spectral variation in $\mathrm{BC}$ refractive indices.

\begin{tabular}{lrr}
\hline Reference & $A$ & $B$ \\
\hline Krekov (1993) & 0.15 & -0.09 \\
d'Almeida et al. (1991) & 0.01 & -0.05 \\
Chang and Charalampopoulos (1990) & 0.23 & -0.22 \\
Schnaiter et al. (2003) & 0.63 & 0.36 \\
Schnaiter et al. (2005) & 0.79 & 0.79 \\
Kirchstetter et al. (2004) & & -0.05 \\
\hline
\end{tabular}

\section{BC AAE}

With BC shape, size distribution, and RI known, it becomes straightforward to calculate the corresponding optical properties at a given wavelength, and we only consider bulk properties averaged over a given size distribution in this study. Multiple numerical models are available to account for the light scattering properties of a cluster of spheres, where the individual spheres of the cluster do not overlapping, and the multiple-sphere T-matrix method (MSTD) developed by Mackowski and Mishchenko (2011) is used in this study. The MSTM is a numerically exact model for light scattering by multiple spheres, and is widely used to study the scattering properties of BC particles. Due to the high accuracy and efficiency provided by the MSTM, it becomes convenient to consider the optical properties of $\mathrm{BC}$ as aggregates of small spherical monomers. In the framework of the MSTM, the BC particles are rigorously treated as FAs shown in Fig. 3 for optical property simulations, so the errors can only be introduced by uncertainties in the particle microphysical properties, and not the numerical model. Furthermore, the MSTM is also capable of considering the interaction among a large sphere and small ones embedded inside the host, which is also the exact configuration for the coated $\mathrm{BC}$ case in this study.

The AAE is widely approximated with the absorptions at two wavelengths using Eq. (2) (Utry et al., 2014; Li et al., 2016), and BC shows notable different AAE values over different ranges of the wavelength spectrum. To obtain the most representative $\mathrm{AAE}$ value, we use $\mathrm{BC}$ absorptions cross sections at multiple wavelengths between 0.3 and $1.0 \mu \mathrm{m}$ in steps of $0.05 \mu \mathrm{m}$, and the best AAE value to fit these cross sections over the spectrum is obtained by a linear regression of the $\log$-transformed data (i.e., between $\ln \left(C_{\text {abs }}(\lambda)\right)$ and $\ln (\lambda)$ in the logarithm format of Eq. 1). Figure 5 illustrates an example of the AAE calculation, in which the averaged bulk absorption cross sections are shown in the logarithmic scale as a function of wavelength. The red crosses in the figure are obtained from the MSTM for the fresh BC particles integrated over the BC lognormal size distribution (with a GMD of $0.12 \mu \mathrm{m}$ and a GSD of 1.5). A wavelength-independent RI of $1.8+0.6 i$ over the entire spectral range are used for the simulation. The absorption cross section shows a clear linear

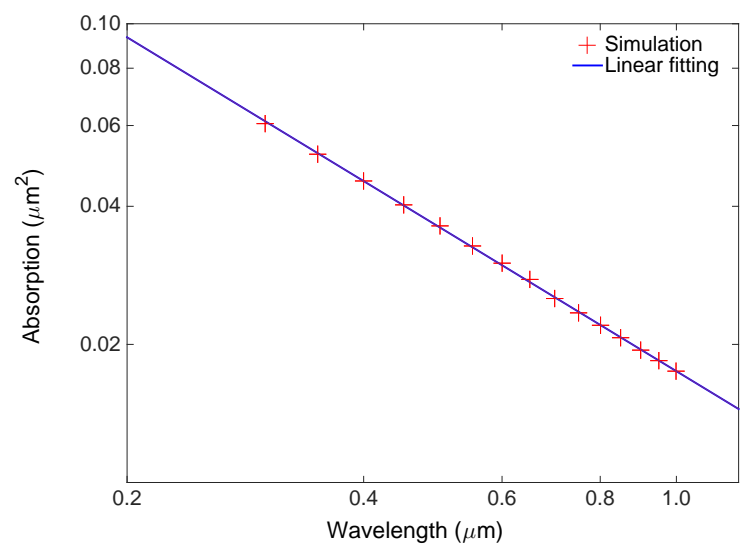

Figure 5. Absorption cross sections of fresh BC with a wavelengthindependent refractive index of $1.8+0.6 i$ and a GMD of $0.12 \mu \mathrm{m}$ as a function of wavelength.

variation in the logarithmic coordinate, as indicated by the blue line, which represents the result of a linear regression fit. Thus, the slope of the line, i.e., 1.04 in this figure, is the $\mathrm{AAE}$ for BC with the corresponding microphysical properties. In this way, the bias introduced by considering absorptions at only two wavelengths can be avoided. It should be noted that the example in the figure shows an excellent linear relationship, which is not true for all cases, whereas linear regression still gives the best representation on the AAE values if the absorption does not accurately decrease exponentially.

Figure 6 shows the calculated BC AAE with a wavelengthindependent RI of $1.8+0.6 i$ using the aforementioned numerical methods, and the sensitivities of BC AAE to particle geometry and size are clearly illustrated. The results for spheres with equivalent volume are also given in the figure and show obviously different variation from those of nonspherical particles, which demonstrates the necessity to consider the complex geometries of BC particles. Different BC conditions in the atmosphere, i.e., fresh, compact, and coated $\mathrm{BC}$, are represented by particles with different geometries. As evident in Fig. 6, even for these relatively small aerosols, geometry has an important influence on the AAE. Moreover, particles with different geometries show different dependences on particle size. D. Liu et al. (2015) pointed out that the AAE could also be sensitive to monomer size, which is fixed to have a radius of $15 \mathrm{~nm}$ in our work. Thus, the shade in Fig. 6 depicts the influences associated with different monomer radii, i.e., $a=10 \mathrm{~nm}$ and $a=20 \mathrm{~nm}$, and all other results shown in this study use a radius of $15 \mathrm{~nm}$ supported by observations. Monomer size is found to be not very impactful on the AAE of lacy aggregates, whereas the AAE may decrease by as much as 0.1 or more for large compact $\mathrm{BC}$ as the monomer radius increases from 10 to $20 \mathrm{~nm}$. The $\mathrm{AAE}$ of the fresh BC is approximately 1.05 and insensitive to particle size, because the interaction between monomers for lacy aggregates are relatively weak and the absorption per 
monomer does not change significantly as the BC aggregate becomes larger. However, based on the Rayleigh theory, the AAE of small BC with a wavelength-independent RI should be 1.0 (Moosmüller and Arnott, 2009), because the Rayleigh absorption for small particles is proportional to $\lambda^{-1}$. Because the Rayleigh approximation underestimates particle absorption for relatively small aggregates as wavelength becomes smaller (see Fig. 1 and the corresponding discussion), especially those with aggregation structures, and thus accurate scattering simulations give AAE values a little bit larger than 1.0 for even small-sized particles with wavelengthindependent RI. Meanwhile, the AAE of the compact and coated $\mathrm{BC}$ is highly sensitive to particle size and decreases sharply with the GMD. The compact BC has smaller AAE than fresh BC and shows an AAE as low as almost 0.8 as the GMD becomes close to $0.2 \mu \mathrm{m}$. For aggregates with a fractal dimension of 2.3, the AAE curve lies right between those of fresh $\left(D_{\mathrm{f}}=1.8\right)$ and compact $\left(D_{\mathrm{f}}=2.8\right) \mathrm{BC}$, and this further demonstrates the clear influence of aggregates structure on BC AAE. The AAE of coated BC is even more sensitive to particle size, decreasing from almost 1.4 to 0.8 . For coated BC with GMD (again, this refers to the GMD of the $\mathrm{BC}$ core, not the total inhomogeneous particle) larger than approximately $0.10 \mu \mathrm{m}$, coating would decrease the AAE of fresh $\mathrm{BC}$, and the coated $\mathrm{BC}$ gives $\mathrm{AAE}$ values comparable (slightly smaller) to those of compact BC with GMD larger than $0.13 \mu \mathrm{m}$. Meanwhile, both those relatively small AAE values obtained for compact and coated BC particles can potentially explain observed small BC AAEs (Kirchstetter et al., 2004; Arnott et al., 2005; Gyawali et al., 2012; Chakrabary et al., 2013). The AAE of fresh BC with a GMD of $0.2 \mu \mathrm{m}$ drops from approximately 1.05 to 0.8 after aging, both of which are close to the observed values and coincident with the changes (from 1.1 to about 0.8 ) of diesel soot from Schnaiter et al. (2005), and the differences may be caused by uncertainties in the RI or coating amount. Even with nonabsorptive coating material, the coating still amplifies BC absorption and changes the BC AAE (C. Liu et al., 2017). Considering the aging processes of $\mathrm{BC}$ aggregates, Fig. 6 shows that, for relatively large $\mathrm{BC}$ particles, both compact and coated $\mathrm{BC}$ particles have smaller AAE than those of the fresh BC with lacy particle structure. The coating amount, structure or material may affect the absorption enhancement at different particle sizes and then the AAE, and this study considers a special but observation-based case. As a result, the conclusion for the coated BC should be more carefully tested for further applications.

The influences of particle RIs on the AAE are illustrated in Fig. 7, and results for the fresh, compact and coated BC are shown from top to bottom panels. Figure 7 considers only wavelength-independent RIs. The left column is for BC particles with a fixed imaginary part of 0.6 but real parts of 1.6, 1.8 , and 2.0, and the right column is for those with the same real part (1.8) but different imaginary parts $(0.4,0.6,0.8$, and 1.0). The BC AAE increases as the real part increases or the

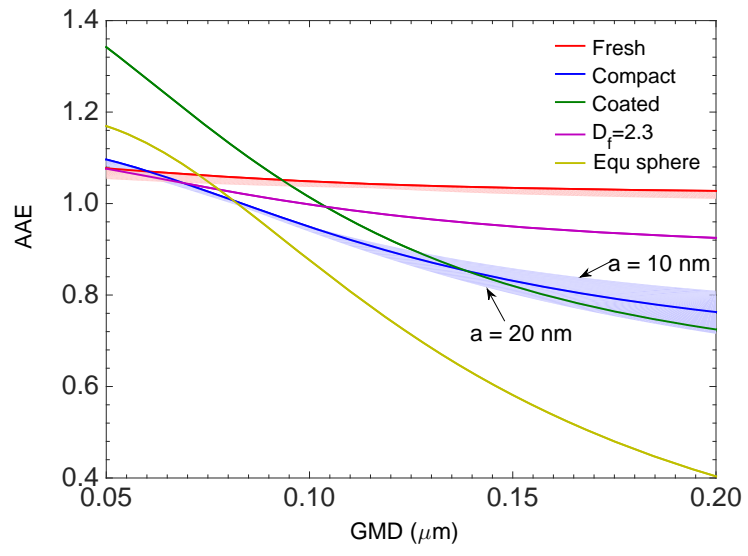

Figure 6. AAEs of the fresh, compact and coated $\mathrm{BC}$ as a function of the volume equivalent GMD of the $\mathrm{BC}$ particles (or $\mathrm{BC}$ core for coated BC).

imaginary part decreases. Although the imaginary part of RI is most directly related to particle absorption, real and imaginary parts affect BC AAE to similar degrees. Again, the sensitivity of BC AAE to its RIs is quite different for particles with different geometries. The AAEs of the fresh BC are less sensitive to RI and show a difference of $<0.1$ for the RIs we considered. As the RI real part increases from 1.6 to 2.0, the AAE of the compact BC increases by approximately 0.15 , and the changes reach as large as 0.3 for the BC imaginary part between 0.4 and 1.0. However, after coating, the AAE becomes less sensitive to the RI real part, but more sensitive to the RI imaginary part. This means that, with the BC core totally embedded within the non-absorptive coating, the absorption enhancement of coated $\mathrm{BC}$ is more sensitive to the imaginary part of BC RI.

All previous studies used a wavelength-independent RI over the entire spectrum, which may or may not be realistic for BC particles in the atmosphere. As explained in Sect. 2.3, parameters $A$ and $B$ are introduced to account for wavelength variance of the real and imaginary parts of RI, respectively. Because BC absorption increases as the real part of RI decreases or the imaginary part increases, it is simple to understand the influence of wavelength-dependent RIs on BC AAE. With simple variations assumed for both RI real and imaginary parts, it becomes possible to quantify the effects of RI wavelength variations. Previous simulations have given BC absorptions at some particular RI values (i.e., real part of 1.6, 1.8, and 2.0, and imaginary part of $0.4,0.6,0.8$, and 1.0), and, to save computational time, BC absorptions at other RIs (which are obtained from Eqs. 4 and 5 with given $A$ and $B$ ) are approximated by interpolation among those existing results. By comparing with accurate MSTD results, we find that the interpolation introduces relative errors of $<1 \%$ for the absorption, which is accurate enough for the AAE simulation. 

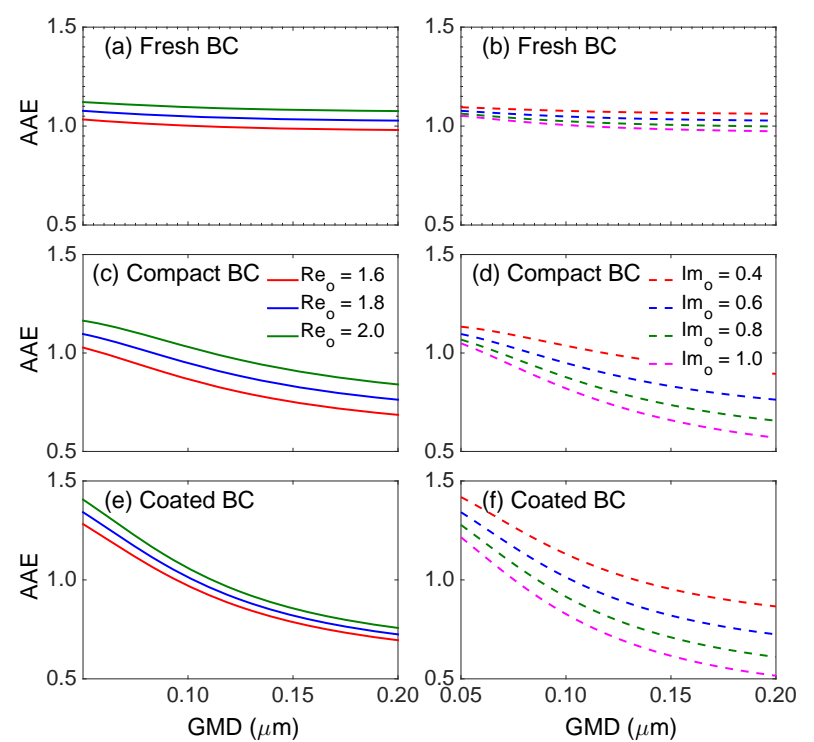

Figure 7. Influence of wavelength-independent refractive index on the AAEs of the fresh BC $(\mathbf{a}, \mathbf{b})$, compact BC $(\mathbf{c}, \mathbf{d})$, and coated $\mathrm{BC}(\mathbf{e}, \mathbf{f})$. A fixed imaginary part of 0.6 is used for panels $(\mathbf{a}, \mathbf{c}, \mathbf{e})$, and a fixed real part of 1.8 is used for panels $(\mathbf{b}, \mathbf{d}, \mathbf{f})$.

Figure 8 illustrates the impacts of wavelength-dependent RIs on BC AAE, and three rows correspond to results for the fresh (top), compact (middle), and coated (bottom) BC. Both $A$ and $B$ are assigned to change between -0.5 and 0.5 . Figure 8 considers two examples for the reference RI at the wavelength of $0.55 \mu \mathrm{m}$, i.e., $\operatorname{Re}_{o}+\operatorname{Im}_{o} i$ $(1.8+0.6 i$ and $1.8+0.8 i)$, and they are marked by the solid and dashed curves, respectively. Meanwhile, three BC equivalent-volume diameter distributions with the GMDs of $0.05,0.12$, and $0.20 \mu \mathrm{m}$ are used, and visualized by the red, blue, and green curves. As expected, the AAE increases as $A$ increases or $B$ decreases, and quite different slopes are shown in different panels. Quantitatively, the AAE of BC with wavelength-dependent RIs for typical values of $A=0.2$ and $B=-0.1$ (Chang and Charalampopoulos, 1990; Krekov, 1993) would be approximately 0.15 larger than those with a wavelength-independent RI, and it becomes more difficult to understand the observed small BC AAE values (Kirchstetter et al., 2004; Gyawali et al., 2012). We focus on two features illustrated by the figure, both of which will be used later to decompose the influences of different $\mathrm{BC}$ properties on AAE. First, for all cases, the AAEs show relatively linear variations as either $A$ or $B$ changes, and thus it becomes easy to quantify the influence of wavelength-dependent RIs on BC AAE. Secondly, different panels show very different AAE variation (slope) over $A$ or $B$, whereas, for each panel, the slopes for different cases (i.e., different curves in a panel) are relatively similar, which means that the influence of both $A$ and $B$ is dependent only on particle geometry. Figure 8 only shows six special but typical cases (two $\operatorname{Re}_{o}+\operatorname{Im}_{o} i$ by
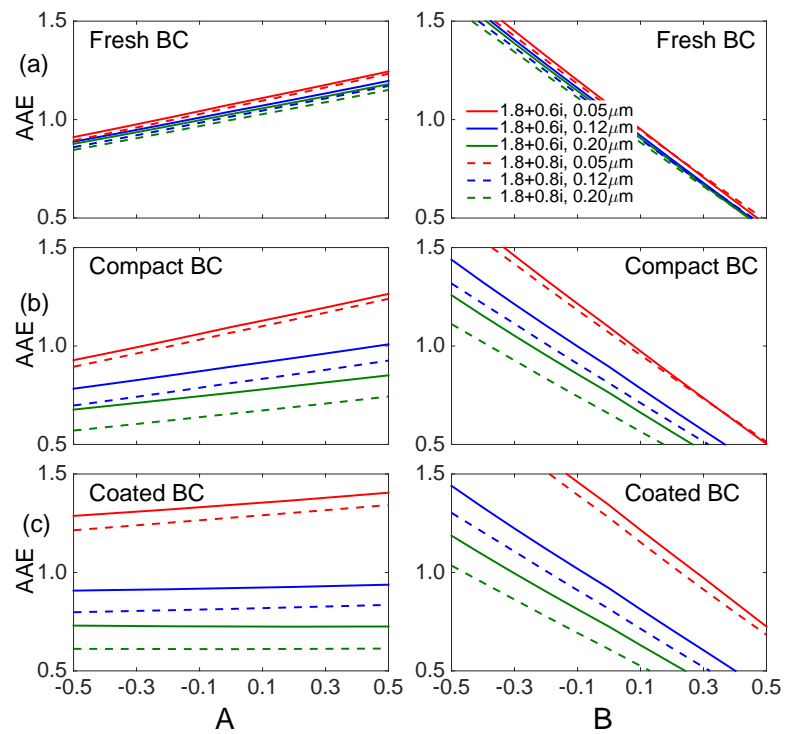

Figure 8. Influence of wavelength-dependent refractive indices on the AAEs of the fresh BC (a), compact BC (b), and coated BC (c).

three GMDs), and more tests were carried out, which show very similar results. Again, it should be noted that, due to the neglect of the dependence on $A$ and $B$ values, these results may overestimate the variability on AAE to some degree.

With all previous factors considered, it becomes possible to decompose the influences of $\mathrm{BC}$ properties on AAE. The $\mathrm{BC}$ properties show clearly monotonic influence on the $\mathrm{AAE}$ but to varying degrees. BC morphology, the most complex property parameterized by multiple parameters (e.g., fractal parameters, coating parameters, and coating amount), cannot be adequately represented by a single variable, whereas it plays the most important and complex role in determining BC AAE. Thus, the morphology is considered independently, and its influence can be considered with other parameters known. To be more specific, the relationships between the BC AAE and the properties besides shape are simply approximated with linear equations for each $\mathrm{BC}$ geometry, and, thus, the BC AAE is expressed by

$$
\begin{aligned}
\mathrm{AAE}= & \mathrm{AAE}_{o}+k_{1} \log \frac{\mathrm{GMD}}{0.12}+k_{2}\left(\operatorname{Re}_{o}-1.8\right) \\
& +k_{3}\left(\operatorname{Im}_{o}-0.6\right),
\end{aligned}
$$

where GMD is given units of microns, and $0.12 \mu \mathrm{m}$ can be understood as the reference size. Considering the AAE variation over different variable, a logarithmic relationship is used for the $\mathrm{BC}$ size, and the relationships related to RI are assumed to be linear. The coefficients, from $k_{1}$ to $k_{3}$, are fitted to indicate the significance of the corresponding influence on $\mathrm{BC}$ AAE. Because the influence of $\mathrm{BC}$ properties on $\mathrm{AAE}$ for particles with different geometries is completely different, we approximate the coefficients of the above equation for the fresh, compact, and coated BC separately. The fitted 
coefficients are given in Table 2. The $\mathrm{AAE}_{o}$ and three coefficients $\left(k_{1}, k_{2}\right.$, and $\left.k_{3}\right)$ in the table are obtained by given the smallest root-mean-square relative errors for all AAE values calculated based on wavelength-independent RIs. The influence of BC properties on AAE are clearly demonstrated by the coefficients in Table 2. Large absolute values mean to have more significant influence on the AAE, and the positive or negative sign indicates the sign of the correlation. The effects of RI wavelength dependence (i.e., $A$ and $B$ in Eqs. 4 and 5), which have been shown in Fig. 8, are not included in Eq. (6), because they are less quantitatively meaningful due to the significant uncertainties on the dependence between $A$ and $B$.

To demonstrate the performance of the simple expresses on approximating BC AAE, Fig. 9 compares BC AAEs from accurate absorption simulations and Eq. (6). The left panel of the figure shows the cases in which the approximations show relatively accurate agreement with the simulations, whereas some examples with relatively poor agreement are illustrated in the right panel. It is clear that the results for the fresh BC show the best agreement because of the relatively weak influence of particle size on the AAE. The relatively poor agreements for the compact and coated $\mathrm{BC}$ are mainly because of the nonlinear variation of the AAE on the GMD. The differences between the accurate simulations (solid curved) and the approximation (dashed lines) can reach slightly over 0.1 for small $\mathrm{BC}$ particles. However, considering that the $\mathrm{BC}$ are widely observed or considered to have a GMD larger than $0.10 \mu \mathrm{m}$, Fig. 9 indicates that the simple linear approximation we obtained give a quite accurate estimation on BC AAE for $\mathrm{BC}$ of the three types.

Our results obtained here indicate that $\mathrm{BC}$ microphysical properties have a clear influence on $\mathrm{BC} \mathrm{AAE}$, and the influence can be quantitatively understood by Eq. (6) and the coefficients listed in Table 2. Considering the obvious variations obtained for $\mathrm{BC}$ particle sizes and geometries and the uncertainties on its RI, it is impossible to find a "best" AAE value for all $\mathrm{BC}$ aerosols. However, a range of reasonable $\mathrm{AAE}$ values can be obtained based on the observations of $\mathrm{BC}$ properties and the numerical results. For fresh BC, the AAEs are approximately 1.05 , and aging causes AAE of typically sized BC particles to decrease by approximately 0.15 to 0.90 . Furthermore, wavelength-dependent RIs make the case much more complicated and give wider ranges of the BC AAE. For coated BC particles, the absorption can also be significantly affected by chemical composition, amount, and geometry of mixing material (Li et al., 2016), and this study introduces a laboratory-based coating amount distribution to reveal the significant effects of coating on BC AAE. With the help of Eq. (6), the BC AAE can be easily calculated if its properties (shape, size, and RI) are known.
Table 2. Fitted coefficients to show the sensitivities of BC properties on AAE values. Two significant figures are kept for all coefficients.

\begin{tabular}{lrrrr}
\hline & $\mathrm{AAE}_{o}$ & $k_{1}$ & $k_{2}$ & $k_{3}$ \\
\hline Fresh BC & 1.05 & -0.04 & 0.24 & -0.13 \\
Compact BC & 0.90 & -0.3 & 0.40 & -0.42 \\
Coated BC & 0.95 & -0.5 & 0.20 & -0.54 \\
\hline
\end{tabular}
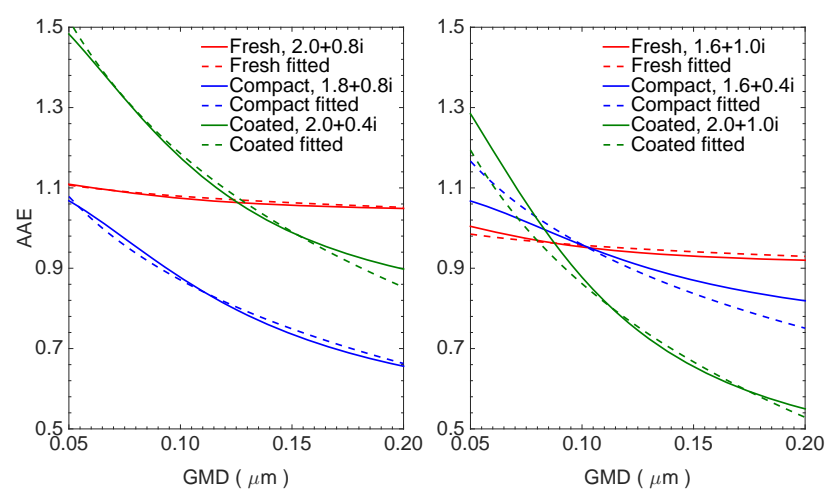

Figure 9. Comparison between the AAEs given by accurate numerical simulations (solid curves) and those approximated by Eq. (6) and the corresponding coefficients in Table 2 (dashed curves).

\section{Summary and conclusions}

We have numerically investigated the AAE of BC aerosols of three states in the atmosphere, i.e., fresh, compact, and coated ones. The numerical computations conducted here have multiple controllable variables (such as BC size distribution) that all effect $\mathrm{BC} \mathrm{AAE}$, and we attempted to constrain these variables within the realistic ranges as determined by observation-based studies. The MSTM was used to accurately compute the light absorption of non-spherical particles, and the numerical results were analyzed to better understand the BC AAE values in relation to the controllable variables.

The results challenge conventional beliefs. With a wavelength-independent refractive index, our accurate numerical results show typical BC AAE values of 1.05 and 0.90 , instead of 1.0, for fresh and aged BC particles respectively. In reality as revealed by many observational studies, the $\mathrm{BC}$ refractive index likely has sizable wavelength dependence, and $\mathrm{BC}$ is often coated by non-BC aerosol materials. In these cases, $\mathrm{BC} \mathrm{AAE}$ can even move beyond a range of $0.5-1.5$. As a result, using a flat value of 1.0 for $\mathrm{BC} \mathrm{AAE}$ could very likely introduce significant errors in aerosol absorption analysis studies.

Our results demonstrate that $\mathrm{BC}$ particle shape is the most influential factor in determining BC AAE. The AAE of fresh $\mathrm{BC}$ in the form of lacy aggregate is less sensitive to particle size, whereas, after aging processes, the $\mathrm{AAE}$ of $\mathrm{BC}$ with 
compact or coated structures may significantly decreases as particle size increases. As the most uncertain particle property, the refractive index cannot be directly measured and thus becomes the most significant challenge in determining BC AAE. To quantify the complicated influences of different $\mathrm{BC}$ parameters on $\mathrm{AAE}$, linear approximations for BC AAEs in different conditions were obtained here. Our results clearly demonstrate the importance of various parameters on the $\mathrm{BC}$ $\mathrm{AAE}$ and the errors of assuming $\mathrm{BC} \mathrm{AAE}$ as 1.0. However, caution should be taken in interpreting our results as a comprehensive guide or absolute reference, because the closure studies between numerical models and observations on $\mathrm{BC}$ properties can be relatively poor (Bond and Bergstrom, 2006; Radney et al., 2014).

Data availability. The data obtained from this study are available upon request from Chao Liu (chao_liu@ nuist.edu.cn).

Competing interests. The authors declare that they have no conflict of interest.

Acknowledgements. We are deeply thankful to Daniel W. Mackowski and Michael I. Mishchekno for the MSTM code. The authors also gratefully acknowledge the effort by the two anonymous reviewers and Joel C. Corbin to improve the manuscript. This work was financially supported by the National Key Research and Development Program of China (2016YFA0602003), the Natural Science Foundation of China (41505018 and 91644224), the Natural Science Foundation of Jiangsu Province (BK20150899), the Young Elite Scientists Sponsorship Program by CAST (2017QNRC001), the US NSF (award no. AGS-1455759), and the Helmholtz Research Program Atmosphere and Climate. The computation of this study was supported by the National Supercomputer Center in Guangzhou (NSCC-GZ).

Edited by: Ari Laaksonen

Reviewed by: three anonymous referees

\section{References}

Alexander, D. T. L., Crozier, P. A., and Anderson, J. R.: Brown carbon spheres in East Asian outflow and their optical properties, Science, 321, 833-836, 2008.

Ångström, A.: On the atmospheric transmission of sun radiation and on dust in the air, I, II, Geogr. Ann., 11, 156-166, 1929.

Arnott, W. P., Hamasha, K., Moosmüller, H., Sheridan, P. J., and Ogren, J. A.: Towards aerosol light-absorption measurements with a 7-wavelength aethalometer: Evaluation with a photoacoustic instrument and 3-wavelength nephelometer, Aerosol Sci. Tech., 39, 17-29, 2005.

Bahadur, R., Praveen, P. S., Xu, Y., and Ramanathan, V.: Solar absorption by elemental and brown carbon determined from spec- tral observations, P. Natl. Acad. Sci. USA, 109, 17366-17371, 2012.

Bergstrom, R. W., Russell, P. B., and Hignett, P.: Wavelength dependence of the absorption of black carbon particles: Predictions and results from the TARFOX experiment and implications for the aerosol single scattering albedo, J. Atmos. Sci., 59, 567-577, 2002.

Bergstrom, R. W., Pilewskie, P., Schmid, B., and Russell, P. B.: Estimates of the spectral aerosol single scattering albedo and aerosol radiative effects during SAFARI 2000, J. Geophys. Res., 108, 8474, https://doi.org/10.1029/2002JD002435, 2003.

Bond, T. C.: Spectral dependence of visible light absorption by carbonaceous particles emitted from coal combustion, Geophys. Res. Lett., 28, 4075-4078, 2001.

Bond, T. C. and Bergstrom, R. W.: Light absorption by carbonaceous particles: An investigative review, Aerosol Sci. Tech., 40, 27-67, 2006.

Bond, T. C. and Sun, H.: Can reducing black carbon emissions counteract global warming?, Environ. Sci. Technol., 39, 59215926, 2005.

Bond, T. C., Covert, D. S., Kramlich, J. C., Larson, T. V., and Charlson, R. J.: Primary particle emissions from residential coal burning: Optical properties and size distribution, J. Geophys. Res., 107, 8347, https://doi.org/10.1029/2001JD000571, 2002.

Bond, T. C., Doherty, S. J., Fahey, D. W., Forster, P. M., Berntsen, T., DeAngelo, B. J., and Zender, C. S.: Bounding the role of black carbon in the climate system: a scientific assessment, J. Geophys. Res., 118, 5380-5552, 2013.

Brasil, A. M., Farias, T. L., and Carvalho, M. G.: Evaluation of the fractal properties of cluster-cluster aggregates, Aerosol Sci. Tech., 33, 440-454, 2000.

Burr, D. W., Daun, K. J., Thomson, K. A., and Smallwood, G. J.: Optimization of measurement angles for soot aggregate sizing by elastic light scattering, through design-of-experiment theory, J. Quant. Spectrosc. Ra., 113, 355-365, 2012.

Chakrabarty, R. K., Moosmüller, H., Garro, M. A., Arnott, W. P., Walker, J., Susott, R. A., and Hao, W. M.: Emissions from the laboratory combustion of wildland fuels: Particle morphology and size, J. Geophys. Res., 111, 1135-1153, 2006.

Chakrabarty, R. K., Moosmüller, H., Arnott, W. P., Garro, M. A., Tian, G., Slowik, J. G., Cross, E. S., Han, J., Davidovits, P., Onasch, T. B., and Worsnop, D. R.: Low fractal dimension cluster-dilute soot aggregates from a premixed flame, Phys. Rev. Lett., 102, 235504, https://doi.org/10.1103/PhysRevLett.102.235504, 2009

Chakrabarty, R. K., Arnold, I. J., Francisco, D. M., Hatchett, B., Hosseinpour, F., Loria, M., Pokharel, A., and Woody, B. M.: Black and brown carbon fractal aggregates from combustion of two fuels widely used in Asian rituals, J. Quant. Spectrosc. Ra., 122, 25-30, 2013.

Chakrabarty, R. K., Beres, N. D., Moosmüller, H., China, S., Mazzoleni, C., Dubey, M. K., Liu, L., and Mishchenko, M. I.: Soot superaggregates from flaming wildfires and their direct radiative forcing, Sci. Rep., 4, 5508, https://doi.org/10.1038/srep18530, 2014.

Chang, H. and Charalampopoulos, T. T.: Determination of the wavelength dependence of refractive indices of flame soot, P. Roy. Soc. A, 430, 577-591, 1990. 
Chow, J. C., Watson, J. G., Doraiswamy, P., Chen, L. A., Sodeman, D. A., Lowenthal, D. H., Park, K., Arnott, W. P., and Motallebi, N.: Aerosol light absorption, black carbon, and elemental carbon at the Fresno Supersite, California, Atmos. Res., 93, 874-887, 2009.

Chung, C. E., Ramanathan, V., and Decremer, D.: Observationally constrained estimates of carbonaceous aerosol radiative forcing, P. Natl. Acad. Sci. USA, 109, 11624-11629, 2012.

Coz, E. and Leck, C.: Morphology and state of mixture of atmospheric soot aggregates during the winter season over Southern Asia - a quantitative approach, Tellus B, 63B, 107-116, 2011.

d'Almeida, G. A., Koepke, P., and Shettle, E. P.: Atmospheric Aerosols, DEEPACK, Hampton, VA, USA, 1991.

Dalzell, W. H. and Sarofim, A. F.: Optical constants of soot and their application to heat-flux calculations, J. Heat Trans., 91, 100-104, 1969.

Dong, J., Zhao, J., and Liu, L.: Morphological effects on the radiative properties of soot aerosols in different internally mixing states with sulfate, J. Quant. Spectrosc. Ra., 165, 43-55, 2015.

Fierce, L., Bond, T. C., Bauer, S. E., Mena, F., and Riemer, N.: Black carbon absorption at the global scale is affected by particle-scale diversity in composition, Nat. Commun., 7, 12361, https://doi.org/10.1038/ncomms12361, 2016.

Filippov, A. V., Zurita, M., and Rosner, D. E.: Fractal-like aggregates: relation between morphology and physical properties, J. Colloid Interf. Sci., 229, 261-273, 2000.

Freney, E. J., Adachi, K., and Buseck, P. R.: Internally mixed atmospheric aerosol particles: hygroscopic growth and light scattering, J. Geophys. Res., 115, D19210, https://doi.org/10.1029/2009JD013558, 2010.

Ganguly, D., Jayaraman, A., Gadhavi, H., and Rajesh, T. A.: Features in wavelength dependence of aerosol absorption observed over central India, Geophys. Res. Lett., 32, L13821, https://doi.org/10.1029/2005GL023023, 2005.

Giles, D. M., Holben, B. N., Eck, T. F., Sinyuk, A., Smirnov, A., Slutsker, I., Dickerson, R. R., Thompson, A. M., and Schafer, J. S.: An analysis of AERONET aerosol absorption properties and classifications representative of aerosol source regions, J. Geophys. Res., 117, D17203, https://doi.org/10.1029/2012JD018127, 2012.

Gyawali, M., Arnott, W. P., Zaveri, R. A., Song, C., Moosmüller, H., Liu, L., Mishchenko, M. I., Chen, L.-W. A., Green, M. C., Watson, J. G., and Chow, J. C.: Photoacoustic optical properties at UV, VIS, and near IR wavelengths for laboratory generated and winter time ambient urban aerosols, Atmos. Chem. Phys., 12, 2587-2601, https://doi.org/10.5194/acp-12-2587-2012, 2012.

Hess, M., Koepke, P., and Schult, I.: Optical properties of aerosols and clouds: The software package OPAC, B. Am. Meteorol. Soc., 79, 831-844, 1998.

Kirchstetter, T. W. and Novakov, T.: Controlled generation of black carbon particles from a diffusion flame and applications in evaluating black carbon measurement methods, Atmos. Environ., 41, 1874-1888, 2007.

Kirchstetter, T. W. and Thatcher, T. L.: Contribution of organic carbon to wood smoke particulate matter absorption of solar radiation, Atmos. Chem. Phys., 12, 6067-6072, https://doi.org/10.5194/acp-12-6067-2012, 2012.

Kirchstetter, T. W., Novakov, T., and Hobbs, P. V.: Evidence that the spectral dependence of light absorption by aerosols is affected by organic carbon, J. Geophys. Res., 109, D21208, https://doi.org/10.1029/2004JD004999, 2004.

Köylü, Ü. Ö., Faeth, G. M., Farias, T. L., and Carvalho, M. G.: Fractal and projected structure properties of soot aggregates, Combust. Flame, 100, 621-633, 1995.

Krekov, G. M.: Models of atmospheric aerosols, in Aerosol Effects on Climate, edited by: Jennings, S. G., University of Arizona, Tucson, AZ, USA, 9-72, 1993.

Lack, D. A. and Cappa, C. D.: Impact of brown and clear carbon on light absorption enhancement, single scatter albedo and absorption wavelength dependence of black carbon, Atmos. Chem. Phys., 10, 4207-4220, https://doi.org/10.5194/acp10-4207-2010, 2010.

Lack, D. A. and Langridge, J. M.: On the attribution of black and brown carbon light absorption using the Ångström exponent, Atmos. Chem. Phys., 13, 10535-10543, https://doi.org/10.5194/acp-13-10535-2013, 2013.

Lack, D. A., Cappa, C. D., Covert, D. S., Baynard, T., Massoli, P., Sierau, B., Bates, T. S., Quinn, P. K., Lovejoy, E. R., and Ravishankara, A. R.: Bias in Filter-based aerosol light absorption measurements due to organic aerosol loading: evidence from ambient measurements, Aerosol Sci. Tech., 42, 1033-1041, 2008.

Lack, D. A., Langridge, J. M., Bahreini, R., Cappa, C. D., Middlebrook, A. M., and Schwarz J. P.: Brown carbon and internal mixing in biomass burning particles, P. Natl. Acad. Sci. USA, 109, 14802-14807, 2012.

Lawless, P. A., Rodes, C. E., and Ensor, D. S.: Multiwavelength absorbance of filter deposits for determination of environmental tobacco smoke and black carbon, Atmos. Environ., 38, 33733383, 2004.

Lewis, K., Arnott, W. P., Moosmüller, H., and Wold, C. E.: Strong spectral variation of biomass smoke light absorption and single scattering albedo observed with a novel dual-wavelength photoacoustic instrument, J. Geophys. Res., 113, 280-288, 2008.

Lewis, K. A., Arnott, W. P., Moosmüller, H., Chakrabarty, R. K., Carrico, C. M., Kreidenweis, S. M., Day, D. E., Malm, W. C., Laskin, A., Jimenez, J. L., Ulbrich, I. M., Huffman, J. A., Onasch, T. B., Trimborn, A., Liu, L., and Mishchenko, M. I.: Reduction in biomass burning aerosol light absorption upon humidification: roles of inorganically-induced hygroscopicity, particle collapse, and photoacoustic heat and mass transfer, Atmos. Chem. Phys., 9, 8949-8966, https://doi.org/10.5194/acp-9-89492009, 2009.

Li, J., Liu, C., Yin, Y., and Kumar, K. R.: Numerical investigation on the Ångström Exponent of black carbon aerosols, J. Geophys. Res., 121, 3506-3518, https://doi.org/10.1002/2015JD024718, 2016.

Liu, C., Panetta, R. L., and Yang, P.: The influence of water coating on the optical properties of fractal soot aggregates, Aerosol Sci. Tech., 46, 31-43, 2012.

Liu, C., Yin, Y., Hu, F., Jin, H., and Sorensen, C. M.: The effects of monomer size distribution on the radiative properties of black carbon aggregates, Aerosol Sci. Tech., 49, 928-940, 2015.

Liu, C., Chung, C. E., Zhang, F., and Yin, Y.: The color of biomass burning aerosols in the atmosphere, Sci. Rep., 6, 28267, https://doi.org/10.1038/srep28267, 2016.

Liu, C., Li, J., Yin, Y., Zhu, B., and Feng, Q.: Optical properties of black carbon aggregates with non-absorptive coating, J. Quant. Spectrosc. Ra., 187, 443-452, 2017. 
Liu, D., Taylor, J. W., Young, D. E., Flynn, M. J., Coe, H., and Allan, J. D.: The effect of complex black carbon microphysics on the determination of the optical properties of brown carbon, Geophys. Res. Lett., 42, 613-619, 2015.

Liu, D., Whitehead, J., Alfarra, M. R., Reyes-Villegas, E., Spracklen, D. V., Reddington, C. L., Kong, S., Williams, P. I., Ting, Y. Haslett, S., Taylor, J. W., Flynn, M. J., Morgan, W. T., McFiggans, G., Coe, H., and Allan, J. D.: Black carbon absorption enhancement in the atmosphere determined by particle mixing state, Nat. Geosci., 10, 184-188, 2017.

Liu, F., Yon, J., and Bescond, A.: On the radiative properties of soot aggregates - Part 2: effects of coating, J. Quant. Spectrosc. Ra., $172,134-145,2016$.

Liu, L. and Mishchenko, M. I.: Effects of aggregation on scattering and radiative properties of soot aerosols, J. Geophys. Res., 110, D11211, https://doi.org/10.1029/2004JD005649, 2005.

Liu, L. and Mishchenko, M. I.: Scattering and radiative properties of complex soot and soot-containing aggregate particles, J. Quant. Spectrosc. Ra., 106, 262-273, 2007.

Lu, Z., Streets, D. G., Winijkul, E., Yan, F., Chen, Y., Bond, T. C., Feng, Y., Dubey, M. K., Liu, S., Pinto, J. P., and Carmichael, G. R.: Light absorption properties and radiative effects of primary organic aerosol emissions, Environ. Sci. Technol., 49, 48684877, 2015.

Mackowski, D. W. and Mishchenko, M. I.: A multiple sphere Tmatrix Fortran code for use on parallel computer clusters, J. Quant. Spectrosc. Ra., 112, 2182-2192, 2011.

Moffet, R. C. and Prather, K. A.: In-situ measurements of the mixing state and optical properties of soot with implications for radiative forcing estimates, P. Natl. Acad. Sci. USA, 106, 1187211877, 2009.

Moosmüller, H. and Arnott, W. P.: Particle optics in the Rayleigh regime, J. Air Waste Manage., 59, 1028-1031, 2009.

Moosmüller, H. and Chakrabarty, R. K.: Technical Note: Simple analytical relationships between Ångström coefficients of aerosol extinction, scattering, absorption, and single scattering albedo, Atmos. Chem. Phys., 11, 10677-10680, https://doi.org/10.5194/acp-11-10677-2011, 2011.

Moosmüller, H., Chakrabarty, R. K., and Arnott, W. P.: Aerosol light absorption and its measurement: A review, J. Quant. Spectrosc. Ra., 110, 844-878, 2009.

Moteki, N., Kondo, Y., and Nakamura, S. I.: Method to measure refractive indices of small nonspherical particles: Application to black carbon particles, J. Aerosol Sci., 41, 513-521, 2010.

Naumann, K.-H.: COSIMA-a computer program simulating the dynamics of fractal aerosols, J. Aerosol Sci., 34, 1371-1397, 2003.

Peng, J., Hu, M., Guo, S., Du, Z., Zheng, J., Shang, D., Zamora, M. L., Zeng, L., Shao, M., Wu, Y., Zheng, J., Wang, Y., Glen, C. R., Collins, D. R., Molina, M. J., and Zhang, R.: Markedly enhanced absorption and direct radiative forcing of black carbon under polluted urban environments, P. Natl. Acad. Sci. USA, 113, 4266-4271, 2016.

Querry, M. R.: Optical constants of minerals and other materials from the millimeter to the ultraviolet, CRDEC-CR-88009, Aberdeen Proving Ground, Aberdeen, MD, USA, 1987.

Radney, J. G., You, R., Ma, X., Conny, J. M., Zachariah, M. R., Hodges, J. T., and Zangmeister, C. D.: Dependence of soot optical properties on particle morphology: measurement and model comparisons, Environ. Sci. Technol., 48, 3169-3176, 2014.
Reddington, C. L., McMeeking, G., Mann, G. W., Coe, H., Frontoso, M. G., Liu, D., Flynn, M., Spracklen, D. V., and Carslaw, K. S.: The mass and number size distributions of black carbon aerosol over Europe, Atmos. Chem. Phys., 13, 4917-4939, https://doi.org/10.5194/acp-13-4917-2013, 2013.

Russell, P. B., Bergstrom, R. W., Shinozuka, Y., Clarke, A. D., DeCarlo, P. F., Jimenez, J. L., Livingston, J. M., Redemann, J., Dubovik, O., and Strawa, A.: Absorption Angstrom Exponent in AERONET and related data as an indicator of aerosol composition, Atmos. Chem. Phys., 10, 1155-1169, https://doi.org/10.5194/acp-10-1155-2010, 2010.

Scarnato, B. V., Vahidinia, S., Richard, D. T., and Kirchstetter, T. W.: Effects of internal mixing and aggregate morphology on optical properties of black carbon using a discrete dipole approximation model, Atmos. Chem. Phys., 13, 5089-5101, https://doi.org/10.5194/acp-13-5089-2013, 2013.

Schmid, O., Artaxo, P., Arnott, W. P., Chand, D., Gatti, L. V., Frank, G. P., Hoffer, A., Schnaiter, M., and Andreae, M. O.: Spectral light absorption by ambient aerosols influenced by biomass burning in the Amazon Basin. I: Comparison and field calibration of absorption measurement techniques, Atmos. Chem. Phys., 6, 3443-3462, https://doi.org/10.5194/acp-6-3443-2006, 2006.

Schnaiter, M., Horvath, H., Möhler, O., Naumann, K.-H., Saathoff, H., and Söchck, O. W.: UV-VIS-NIR spectral optical properties of soot and soot-containing aerosols, J. Aerosol Sci., 34, 14211444, 2003.

Schnaiter, M., Linke, C., Möhler, O., Naumann, K. H., Saathoff, H., Wagner, R., and Schurath, U.: Absorption amplification of black carbo internally mixed with secondary organic aerosol, J. Gephys. Res., 110, D19204, https://doi.org/10.1029/2005JD006046, 2005.

Schnaiter, M., Gimmler, M., Llamas, I., Linke, C., Jäger, C., and Mutschke, H.: Strong spectral dependence of light absorption by organic carbon particles formed by propane combustion, Atmos. Chem. Phys., 6, 2981-2990, https://doi.org/10.5194/acp-6-29812006, 2006.

Schuster, G. L., Dubovik, O., and Holben, B. N.: Angstrom exponent and bimodal aerosol size distributions, J. Geophys. Res., 111, D07207, https://doi.org/10.1029/2005JD006328, 2006.

Seinfeld, J. H. and Pandis, S. N.: Atmospheric chemistry and physics: from air pollution to climate change, John Wiley and Sons, Hoboken, NJ, USA, 2016.

Skorupski, K. and Mroczka, J.: Effect of the necking phenomenon on the optical properties of soot particles, J. Quant. Spectrosc. Ra., 141, 40-48, 2014.

Smith, A. J. A. and Grainger, R. G.: Simplifying the calculation of light scattering properties for black carbon fractal aggregates, Atmos. Chem. Phys., 14, 7825-7836, https://doi.org/10.5194/acp14-7825-2014, 2014.

Sorensen, C. M.: Light scattering by fractal aggregates: a review, Aerosol Sci. Tech., 35, 648-687, 2001.

Sorensen, C. M. and Roberts, G. C.: The prefactor of fractal aggregates, J. Colloid Interf. Sci., 186, 447-452, 1997.

Stagg, B. J. and Charalampopoulos, T. T.: Refractive indices of pyrolytic graphite, amorphous carbon, and flame soot in the temperature range $25^{\circ}$ to $600^{\circ} \mathrm{C}$, Combust. Flame, 94, 381-396, 1993.

Subramanian, R., Roden, C. A., Boparai, P., and Bond, T. C.: Yellow beads and missing particles: Trouble ahead for filter-based absorption measurements, Aerosol Sci. Tech., 41, 630-637, 2007. 
Utry, N., Ajtai, T., Filep, Á., Pintér, M., Török, Z., Bozóki, Z., and Szabó, G.: Correlation between absorption Angström exponent of wintertime ambient urban aerosol and its physical and chemical properties, Atmos. Environ., 91, 52-59, 2014.

Vanhulle, P., Talbaut, M., Weill, M., and Coppalle, A.: Inversion method and experiment to determine the soot refractive index: application to turbulent diffusion flames, Meas. Sci. Technol., 13, 375-382, 2002.

Wang, Q. Y., Huang, R.-J., Cao, J. J., Tie, X. X., Ni, H. Y., Zhou, Y. Q., Han, Y. M., Hu, T. F., Zhu, C. S., Feng, T., Li, N., and Li, J. D.: Black carbon aerosol in winter northeastern Qinghai-Tibetan Plateau, China: the source, mixing state and optical property, Atmos. Chem. Phys., 15, 13059-13069, https://doi.org/10.5194/acp-15-13059-2015, 2015.
Wang, Y., Liu, F., He, C., Bi, L., Cheng, T., Wang, Z., Zhang, H., Zhang, X., Shi, Z., and Li, W.: Fractal dimensions and mixing structures of soot particles during atmospheric processing, Environ. Sci. Tech. Let., 4, 487-493, 2017.

Weingartner, E., Saathoff, H., Schnaiter, M., Streit, N., Bitnar, B., and Baltensperger, U.: Absorption of light by soot particles: determination of the absorption coefficient by means of aethalometers, J. Aerosol Sci., 34, 1445-1463, 2003.

Wu, Y., Cheng, T., Zheng, L., and Chen, H.: Effect of morphology on the optical properties of soot aggregated with spheroidal monomers, J. Quant. Spectrosc. Ra., 168, 158-169, 2016.

Yon, J., Bescond, A., and Liu, F.: On the radiative properties of soot aggregates - Part 1: necking and overlapping, J. Quant. Spectrosc. Ra., 162, 197-206, 2015. 